\title{
Study of Management of Second Degree Burns with Topical Heparin
}

\author{
Dr. R. G. Naniwadekar ${ }^{1}$, Dr. Sangeeta Biradar ${ }^{2}$, Dr. Basavaraj Nagur ${ }^{3}$, Dr. Jignesh Savsaviya ${ }^{4}$ \\ Krishna Institute of Medical Science, Deemed University Karad
}

\begin{abstract}
Introduction: Burn injuries are known for their complexity therefore its treatment requires a complete understanding of patho-physiology and interaction of the major organ systems. In India burn injuries account for most of the hospital admissions. Various treatment options are available for burn wound management. Heparin as an option for treatment of burn wounds has been found to useful; hence we decided to study their effectiveness in burn wound management. Aims: In view of the above said we considered to study the effectiveness of heparin dressing in treating burns. Methodology: A prospective study was done in KIMSDU Karad in for 1 year December 2014 to December 2015 in which 50 patient with second degree superficial burns with less than 24 hrs were chosen for the study admitting in the burn unit of KIMSDU. Results: Total 50 patients were included in study group over a period of 1 year all the patient were with second degree thermal burns less than 24 hrs. Conclusion: Heparin can be applied safely in the treatment of superficial second degree burns.
\end{abstract}

Keywords: burns, heparin, second degree

\section{Introduction}

Burn injuries are known for their complexity therefore its treatment requires a complete understanding of pathophysiology and interaction of the major organ systems. In India burn injuries account for most of the hospital admissions. Various treatment options are available for burn wound management. Heparin as a option for treatment of burn wounds has been found to useful, hence we decided to study their effectiveness in burn wound management.

Pathophysiology of burns is summarized by two main events: edema and an increase in capillary hydrostatic pressure. Thermal injury induces a cascade of systemic inflammatory reactions by the exposure of the subendothelial collagen. This cascade results in tissue oedema and hypovolemia. Activation of the kallikrein system produces cytokinins that aggravate both the oedema and hypovolemia.Cytokinin and collagen exposure activate the arachnoid acid-phospholipase system, liberating prostaglandins and, increasing capillary permeability. Locally substance P, Serotonin, nitric oxide, Bradykinin and leukotrienes play a role in increased local capillary permeability.

\section{Materials and Methods}

Study is conducted in KIMSDU Krishna institute of medical sciences deemed university karad in the year 2015 and 2016 over 1 year total 30 patients were studied with second degree superficial burns.

\section{Procedure}

Heparin treatment was started as soon as the patient came to the Burns Ward after the initial assessment and resuscitation was complete and was continued till seven post burn day and stopped if the patient was taken up for any form of surgical intervention. The affected area was thoroughly cleaned for removal of any external contamination. On Post-burn Day 1 total topical heparin dose is approximately 100,000 IU per
$15 \%$ body surface area (BSA) burn size in three divided doses for 5 days at $9 \mathrm{am}, 3 \mathrm{pm}$ and $9 \mathrm{pm}$ each day. In this modification the same dosage is given for the first 2 days, 3 and 4 are also the same with $75 \%$ of that of Day 1 while Day 5,6 and 7 is reduced to $50 \%$. During each time of application, applied in 3 cycles with 5-10 minutes interval, sprinkling the heparin on the burned surface with a gauge and "\#29" needle. For blisters syringe filled with $5000 \mathrm{IU} / \mathrm{ml}$ heparin solution is inserted into the blister and a small hole made that allows the burn fluid to drain. Then slowly the heparin solution from the syringe is inserted into the blister. After the blister is filled and the solution begins to run out, injecting the heparin solution is continued. This creates a rinsing action. The blister is filled up and rinsed out approximately 3 times. This cycle is repeated two to three times at 5 to 10 minutes intervals. Heparin solution is left within the blister before removing the needle for the final time. If the wound was infected, the wound was debrided properly before dressing. The side effects of heparin and/or alteration of the bleeding profile were monitored and if present were a definitive indication for stopping heparin, and the effects reversed with protamine sulphate $1 \mathrm{ml}$ diluted with $9 \mathrm{ml}$ of distilled water over ten minutes. Dressings were changed daily.

\section{Statistics}

Gender ratio
\begin{tabular}{|c|c|c|}
\hline Gender & Male & Female \\
\hline Total no of patient & 12 & 38 \\
\hline percentage & $24 \%$ & $76 \%$ \\
\hline
\end{tabular}




\section{International Journal of Science and Research (IJSR) \\ ISSN (Online): 2319-7064}

Index Copernicus Value (2013): 6.14 | Impact Factor (2014): 5.611

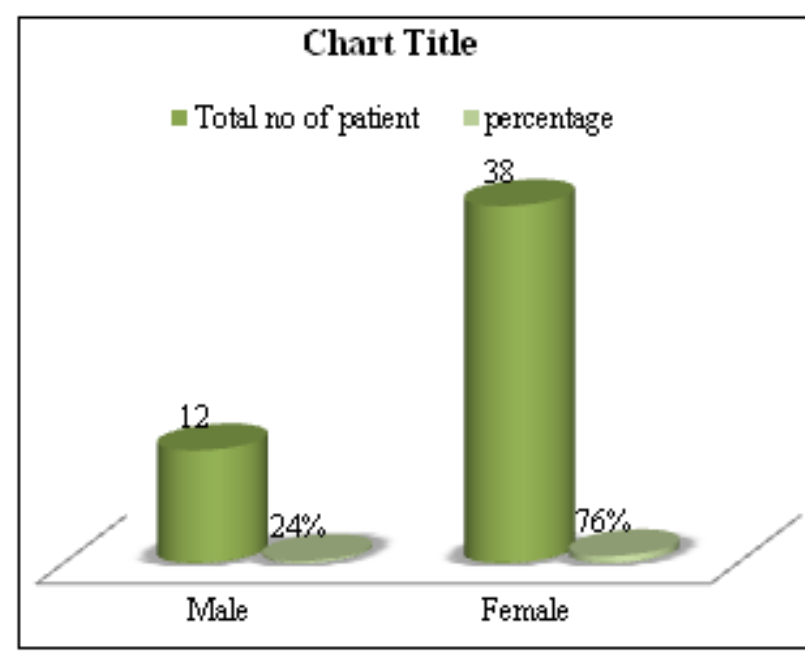

Age distribution
\begin{tabular}{|c|c|c|}
\hline Age & Male & Female \\
\hline $0-20$ & 3 & 12 \\
\hline $21-40$ & 5 & 18 \\
\hline $40-60$ & 4 & 8 \\
\hline Total & 12 & 38 \\
\hline
\end{tabular}

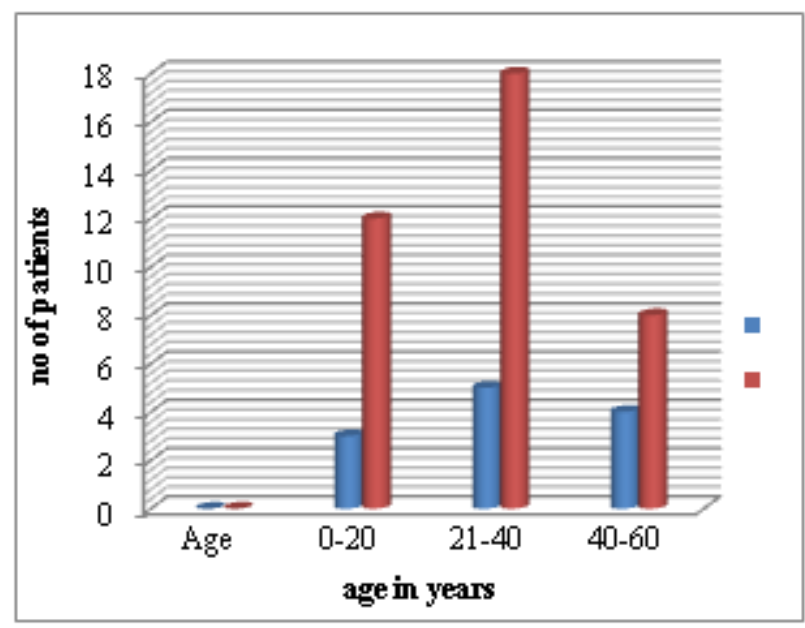

Percentage of burns
\begin{tabular}{|c|c|}
\hline Percentage of burns & No of patients \\
\hline$<25$ & 37 \\
\hline $25-50$ & 13 \\
\hline
\end{tabular}

In our study it was observed that females were in the group as compared to males of same age group.25-50\% of burns are common with most of the patient presenting in this group. Time taken for recovery is $2-3$ weeks and hospital stay was on an average 12- 16 days.

\section{Discussion}

Burns are painful wounds. The sufferings and sequelae of burn victims are disasterous. Burn sequels affect life quality and produce longstanding emotional and social impacts in the patient's life. The development of new treatment resources could modify this picture. In this study, a new treatment approach using topical heparin was used to relieve pain, enhance healing, and produce smooth skin in burn unit of KIMSDU. Patients in the study group were brought to the burn unit of KIMSDU by the family members in severe pain and in poor conditions. Conventional treatment of burns would have taken longer period to manage the pain, initiate healing (re-epithelization) and alleviate the formation of scars. Pain conditions in the patients were quickly alleviated with each passing day, hence patients in this topical heparin study reported less pain while consuming less analgesic medication as compare to patients in similar conditions who were treated with the conventional approach (high dosage of analgesic medication), with the normal management routine in the burn unit.

Heparin is an antagonist to histamine, bradykinin, and prostaglandin E1 combined with platelets inhibited complement $\mathrm{C} 1$ esterase; protective against toxic oxygen metabolites and it also bound to tumor-necrosis-factor ${ }^{1}$. Heparin is a naturally-occurring anticoagulant produced by basophils and mast cells ${ }^{2}$

The work of Ramakrishna ${ }^{3}$ showed that heparin when used in the management of burns, had anti-inflammatory properties.

The work of Saliba ${ }^{4}$ proved that when heparin was added in the management of burns, not only did it reduce pain, but, also limited the inflammation, caused revascularization of ischemic tissue and enhanced tissue granulation.

Heparin therapy consistently relieved pain, reduced inflammation, limited cellular-destruction, was neoangiogenic, regulated tissue restoration, shortened and facilitated healing and resulted in smooth healing. Patients were more alert, physically active, cooperative, able to eat and help in their care. There was a significant reduction in need for escharotomies and fasciotomies and skin grafting ${ }^{5,6,7}$.

According to the reports of Peplow and Wang et al., a persistent inflammation with the accumulation of large numbers of neutrophils is characteristic of chronic wounds. Secretory products released from these cells, such as elastase, cathepsin $\mathrm{G}$ and proteinases, are detrimental to wound healing because they degrade the extracellular matrix and growth factors and further recruit neutrophils to the wound area. Heparin and related molecules are thought to inhibit the action of these secretory products via electrostatic interactions ${ }^{[8,9]}$. Even, skin pigmentation started as early as Day 7 for some of the patients coupled with a well smooth skin. Heparin is affordable and may be economically advantageous for the health system and more comfortable to the patient. Finally, due to characteristics of sprayed topical heparin treatment system (simplicity and comfort), its incorporation to burn treatment centers' routine may be advantageous for the patient.

\section{Conclusion}

Topical heparin was observed to be very effective in the management of burns injuries. It was Effective in the alleviation of pains. Also time spent by patients during admission reduced making it less costly for the patients. The patients involved in this case reports significantly benefited from the topical application of heparin. However, due to the small number of patients and lack of control for the wound healing, a firm recommendation for the use of heparin 


\section{International Journal of Science and Research (IJSR) \\ ISSN (Online): 2319-7064}

Index Copernicus Value (2013): 6.14 | Impact Factor (2014): 5.611

therapy in burns cannot be made and further studies would be required to establish its use.

\section{References}

[1] Guyton, A. C.; Hall, J. E. (2006). Textbook of Medical Physiology. Elsevier Saunders. p. 464.

[2] Marcum JA (January 2000). "The origin of the dispute over the discovery of heparin". Journal of the History of Medicine and Allied Sciences 55 (1): 37-66.

[3] Ramakrishnan K, Jayaraman V. Efficacy of low molecular weight heparin in wound healing. Buns Feb 2007, 33:1; 158-159.

[4] Saliba Jr. M. Burn treatment with heparin added. Burns Feb 2007, 33: 1 S35.

[5] M.J. Saliba, Jr, Heparin in the treatment of burns. J. Am. Med. Assoc. 200 (1967), p. 650.

[6] J. Saliba, Jr, Heparin efficacy in burns. II. Human thermal burn treatment with large doses of topical and parenteral heparin. Aerosp. Med. 41 (1970), p. 1302.

[7] M.J. Saliba, Jr, W.C. Dempsey and J.L. Kruggel, Large burns in humans, treatment with heparin. J. Am. Med. Assoc. 225 (1973), p. 261.

[8] Peplow PV. Glycosaminoglycan: a candidate to stimulate the repair of chronic wounds. Thromb

[9] Haemost 2005; 94: 4-16.

[10] Wang J, Zheng H, Qiu X. Modulation of the intestinal response to ionizing radiation by anticoagulant and nonanticoagulant heparins. Thromb Haemost 2005; 94: 1054-9.

\section{Author Profile}

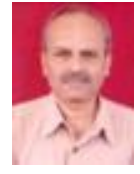

Dr. R.G. Naniwadekar has received MBBS degree from B.J Medical college pune in 1979. MS from B.J medical College pune in 1987.Currently he is working as Associate Professor in Gen. Surgery department at Krishna Hospital Karad. He has presented research paper in national journal

Dr. Sangeeta Biradar has received MBBS degree from KBNIMS college in 2009. Since May 2013 she is postgraduate student in Gen. Surgery department at Krishna Hospital Karad. He has presented research paper in national journal and international journal

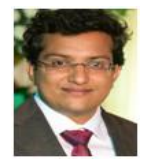

Dr. Basavaraj Nagur has received MBBS degree from Shri B.M.P.M.C. Bijapur from 2007-2013. Since May 2013 he is postgraduate student in Gen. Surgery department at Krishna Hospital Karad. He has international journal presented research paper in national journal and

Dr.Jignesh .Savsaviya has received MBBS degree from soochow university, China from 2007 2012.Since May 2013 he is postgraduate student in Gen. Surgery department at Krishna Hospital Karad. He has presented research paper in national journal 